\title{
Evaluation of antioxidant activity and cytotoxic potential of Cryptocoryne ciliata
}

\author{
*Ummey Jannatun Nahar, Shah Marzia Mahjabin Lina \\ Department of Pharmacy, Stamford University Bangladesh, 51, Siddeswari Road, Dhaka-1217, Bangladesh
}

\begin{abstract}
Cryptocoryne ciliata belonging to the Araceae family has been investigated for isolation of its secondary metabolites and evaluation of biological activities of the crude extractives with special emphasis to the antioxidant activity and brine shrimp lethality bioassay. The whole plant was extracted with methanol and concentrated extract was partitioned using petroleum ether, carbon tetrachloride and ethyl acetate. Aqueous soluble fraction of the methanolic extract showed the highest antioxidant activity. The carbon tetrachloride soluble fraction of the methanolic extract and the ethyl acetate soluble fraction of the methanolic extract showed moderate antioxidant activity as compared to free antioxidant activity of tert-butyl-1-hydroxytolunene. In the brine shrimp lethality bioassay, among all extracts of whole plant of $C$. ciliata, the carbon tetrachloride soluble fraction of the methanolic extract showed strong cytotoxic activity. Aqueous soluble fraction of the methanolic extract, methanolic crude and ethyl acetate soluble fraction of the methanolic extract showed mild cytotoxity as compared to that of vincristine sulphate. The study confirms the mild to moderate antioxidant and moderate potent cytotoxic activities of $C$. ciliata plant extract as compared to reference standards and therefore demands the isolation of active principles and thorough bioassay.
\end{abstract}

Key Words: Artemia salina, bioactive compound, cytotoxicity, brine shrimp lethality bioassay, free radical scavenging activity, nauplii.

\section{INTRODUCTION}

Nature has been a source of medicinal agents for thousands of years and an impressive number of modern drugs have been isolated from natural sources, many based on their use in traditional medicine. The widespread use of herbal remedies and healthcare preparations, such as those described in ancient texts like the Vedas and the Bible, has been traced to the occurrence of natural products with medicinal properties. In fact, plants produce a diverse range of bioactive compound, making them a rich source of different types of medicines. Higher plants, as sources of medicinal compounds, have continued to play a dominant role in the maintenance of human health since ancient times (Farombi, 2003). Over $50 \%$ of all modern clinical drugs are of natural product origin (Stuffness and Douros, 1982)

\footnotetext{
*Corresponding Author:

Ummey Jannatun Nahar, Lecturer

Department of Pharmacy

Stamford University Bangladesh

51, Siddeswari Road, Dhaka-1217, Bangladesh

E-mail: nahar.jannatun@yahoo.com

Contact No.: +8801916155157
}

and natural products play an important role in drug development programs in the pharmaceutical industry (Baker et al., 1995). In the present study whole plant of Cryptocoryne ciliata was used to evaluate antioxidant activity and cytotoxic potentiality of it. Antioxidant in compounds plays an important role as a health-protecting factor. The role of free radicals in our body generates reactive oxygen species and these are capable of damaging crucial bio-molecules. If they are not effectively scavenged by cellular constituents, they lead to disease conditions (Halliwell and Gutteridge, 1989).

Bioactive compounds are almost always toxic to living body at some higher doses. Brine shrimp lethality bioassay (McLaughlin et al., 1998; Persoone, 1980 ) is a rapid and comprehensive bioassay for the bioactive compounds of natural and synthetic origin. By this method, natural product extracts, fractions as well as pure compounds can be tested for their bioactivity. In this method In vivo lethality in a simple zoological organism (Brine shrimp nauplii) is used as a favorable monitor for screening 
and fractionation in the discovery of new bioactive natural products (Meyer et al., 1982). This bioassay indicates cytotoxicity as well as a wide range of pharmacological activities such as antimicrobial, antiviral, pesticidal and anti-tumor etc. of the compounds (Meyer et al., 1982; McLaughlin et al., 1998).

\section{MATERIALS AND METHODS}

Plant sample of Cryptocoryne ciliata was collected from Khulna in September 2010. The whole plant part(s) was collected in fresh condition. It was sundried and then it was oven-dried at reduced temperature (not more than $50^{\circ} \mathrm{C}$ ) to make it suitable for grinding purpose. The dried whole plant was then crushed into coarse powder by a high capacity grinding machine. The powdered material was extracted with methanol with the help of a soxlet apparatus in the Phytochemical Research Laboratory, Faculty of Pharmacy, University of Dhaka. The solvent was evaporated to obtain a solid residue. $5 \mathrm{gm}$ of methanol extract of whole plant was triturated with $90 \%$ methanol. The crude extract was dissolved completely. This was mother solution, which was fractioned successfully by three solvents of different polarity such as petroleum ether, carbon tetrachloride and ethyl acetate.

A simple method that has been developed to determine the antioxidant activity of plant extract utilizes the stable 2,2-diphenyl-1-picrylhydrazyl (DPPH) radical (Brand-Williams et al., 1995). The odd electron in the DPPH free radical gives a strong absorption maximum at $517 \mathrm{~nm}$ and purple in color and it is compared to that of tert-butyl-1hydroxytolunene (BHT) by UV spectrophotometer. The color turns from purple to yellow as the molar absorptivity of the DPPH radical at $517 \mathrm{~nm}$ reduces from 9660 to 1640 when the odd electron of DPPH radical becomes paired with hydrogen from a free radical scavenging antioxidant to form the reduced $\mathrm{DPPH}-\mathrm{H}$. The resulting decolorization is stoichiometric with respect to number of electrons captured (Choi et al., 2000; Desmarchelier et al., 1997).

The methanolic extract of the whole plant (ME) and the different partitionate of the methanolic extract of the whole plant i.e. aqueous soluble partitionate $(\mathrm{AQ})$, petroleum ether soluble partitionate (PE), carbon tetrachloride soluble partitionate (CTC) and ethyl acetate soluble partitionate (EA) of Cryptocoryne ciliata were subjected to DPHH method. $2 \mathrm{ml}$ of a methanol solution of the extract at different concentration $(0.500$ to $0.977 \mu \mathrm{g} / \mathrm{ml})$ were mixed with $3 \mathrm{ml}$ of a DPPH methanol solution $(20 \mu \mathrm{g} / \mathrm{ml})$. After $30 \mathrm{~min}$ reaction period at room temperature in dark place, the absorbance was measured at $517 \mathrm{~nm}$ against methanol as blank by UV spectrophotometer. Inhibition free radical DPPH in percent (I\%) was calculated as follows:

$I \%=\frac{1-A_{\text {sample }}}{A_{\text {blank }}} \times 100$,

where Ablank is the absorbance of the control reaction (containing all reagent except the test material).

The methanolic extract of the whole plant (ME) and the different partitionate of the methanolic extract of the whole plant i.e. aqueous soluble partitionate $(\mathrm{AQ})$, petroleum ether soluble partitionate (PE), carbon tetrachloride soluble partitionate (CTC) and ethyl acetate soluble partitionate (EA) of Cryptocoryne ciliata were subjected to brine shrimp lethality bioassay (Meyer et al., 1982). All the test samples (ME, AQ, PE, CTC and EA) were taken in vials and dissolved in $100 \mu \mathrm{l}$ of pure dimethyl sulfoxide (DMSO) to get stock solution. Then $50 \mu \mathrm{l}$ of this solution was taken in the first test tube containing $5 \mathrm{ml}$ of sea water and 10 shrimp nauplii. Thus the final concentration of the prepared of the first test tube was $800 \mu \mathrm{g} / \mathrm{ml}$. Then a series of solutions of varying concentrations were prepared from the stock solution by serial dilution method. In every case, $50 \mu \mathrm{l}$ of the test samples were added to the test tube and fresh $50 \mu \mathrm{l}$ DMSO was added to the vial. Thus different concentrations were found in the different test tubes. Control groups were used in the cytotoxicity study to validate the test method and ensure that the result obtained are only due to the activity of the test agent and the effects of the other possible factors are nullified. In the present study vincristine sulphate was used as the positive control. Measured amount of the vincristine sulphate was dissolved in DMSO to get an initial concentration of $20 \mu \mathrm{g} / \mathrm{ml}$ from which serial dilutions were done using DMSO to get solutions of concentrations $10 \mu \mathrm{g} / \mathrm{ml}, \quad 5 \mu \mathrm{g} / \mathrm{ml}, \quad 2.5 \mu \mathrm{g} / \mathrm{ml}$, $1.25 \mu \mathrm{g} / \mathrm{ml}, 0.625 \mu \mathrm{g} / \mathrm{ml}, 0.3125 \mu \mathrm{g} / \mathrm{ml}, 0.15625 \mu \mathrm{g} / \mathrm{ml}$, $0.078125 \mu \mathrm{g} / \mathrm{ml}$ and $0.039 \mu \mathrm{g} / \mathrm{ml}$. The positive control 
Table 1: IC 50 value of standard and different partitionates Cryptocoryne ciliata.

\begin{tabular}{lll}
\hline Code & Sample & IC $50(\mu \mathrm{g} / \mathbf{m l})$ \\
\hline BHT & Tert-butyl-1-hydroxytolune (standard) & 16.73 \\
AS & Ascorbic acid (standard) & 1.94 \\
ME & Methanolic extract & 27.22 \\
AQ & Aqueous soluble partitionate of methanol extract & 7.25 \\
CTC & Carbontetrachloride soluble partitionate of methanol extract & 13.79 \\
EA & Ethyl acetate soluble partitionate of methanol extract & 22.90 \\
\hline
\end{tabular}

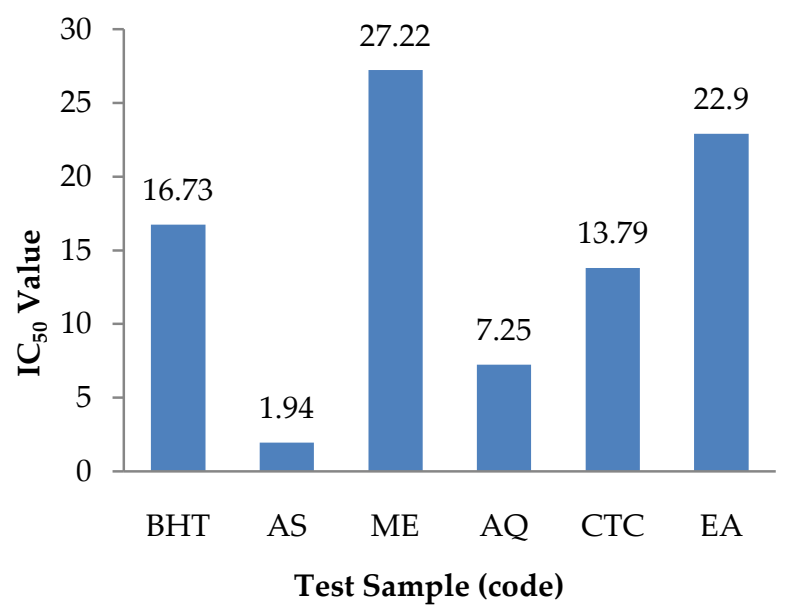

Figure 1: IC 50 values of standards \& different partitionates of Cryptocoryne ciliata.

solution was added to the pre-marked vials containing 10 living shrimps nauplii in $5 \mathrm{ml}$ simulated sea water to get positive control group result. 50 $\mathrm{ul}$ DMSO was added to each three pre-marked glass vials containing 10 living shrimps nauplii in $5 \mathrm{ml}$ simulated sea water to use as negative control group. If the brine shrimps in these vials showed a rapid mortality rate, the test was considered as invalid as the nauplii died due to some reason other than the cytotoxicity of the compounds.

\section{RESULTS AND DISCUSSION}

Extract concentration providing 50\% inhibition (IC50) was calculated from the graph plotted inhibition percentage against extract concentration and the results are given in Table 1 and Figure 1. Here BHT was used as positive control.

In this investigation, the methanolic extract (ME), aqueous (AQ), carbon tetrachloride (CTC) and ethyl acetate (EA) soluble partitionate of the whole plant showed the free radical scavenging activity with

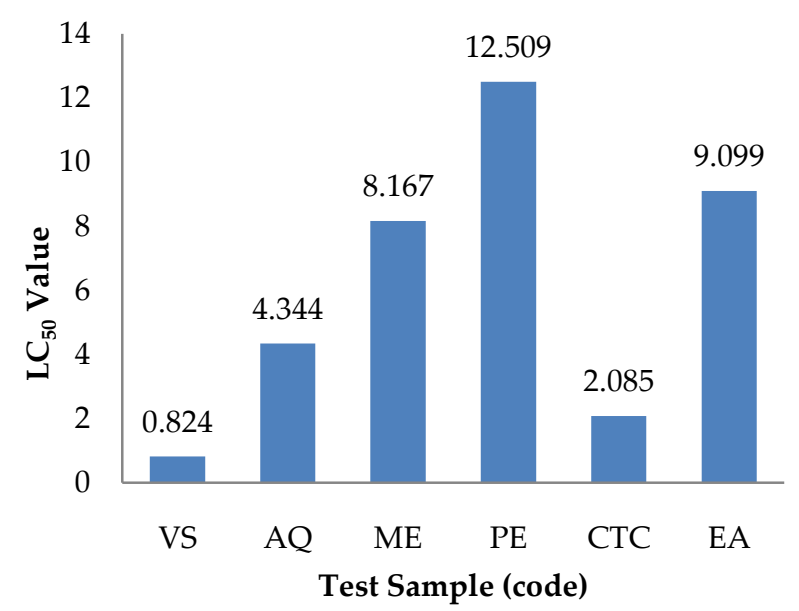

Figure 2: $\mathrm{LC}_{50}$ values of the different extractives of Cryptocoryne ciliata.

IC 50 value $27.22 \mu \mathrm{g} / \mathrm{ml}, 7.25 \mu \mathrm{g} / \mathrm{ml}, 13.79 \mu \mathrm{g} / \mathrm{ml}$ and $22.90 \mu \mathrm{g} / \mathrm{ml}$, respectively.

The lethal concentration ( $\mathrm{LC}_{50}$ ) of the test samples after 24 hours was obtained by a plot of percentage of the shrimps died against the logarithm of the sample concentration (toxicant concentration) and the best-fit line was obtained from the curve data by means of regression analysis. The lethality of the extractives to brine shrimps was determined and the results are given in Table 2 and Figure 2.

Table 2: $\mathrm{LC}_{50}$ and $\mathrm{LC}_{90}$ values of the test samples of Cryptocoryne ciliata.

\begin{tabular}{lllll}
\hline $\begin{array}{l}\text { Test } \\
\text { Samples }\end{array}$ & $\begin{array}{l}\text { Regression } \\
\text { equation }\end{array}$ & $\mathbf{R}^{2}$ & $\begin{array}{l}\text { LC }_{50} \\
\text { values }\end{array}$ & $\begin{array}{l}\mathbf{L C}_{90} \\
\text { values }\end{array}$ \\
\hline VS & $\mathrm{y}=33.21 \mathrm{x}+52.78$ & 0.971 & 0.824 & 13.205 \\
$\mathrm{AQ}$ & $\mathrm{y}=22.95 \mathrm{x}+35.36$ & 0.974 & 4.344 & 240.341 \\
ME & $\mathrm{y}=29.8 \mathrm{x}+22.82$ & 0.976 & 8.167 & 179.623 \\
PE & $\mathrm{y}=33.22 \mathrm{x}+13.55$ & 1.000 & 12.509 & 200.136 \\
CTC & $\mathrm{y}=24.76 \mathrm{x}+42.10$ & 0.953 & 2.085 & 86.015 \\
EA & $\mathrm{y}=34.63 \mathrm{x}+16.79$ & 0.974 & 9.099 & 130.036 \\
\hline
\end{tabular}


The $\mathrm{LC}_{50}$ values of $\mathrm{AQ}, \mathrm{ME}, \mathrm{PE}, \mathrm{CTC}$ and EA were found to be $4.344 \mu \mathrm{g} / \mathrm{ml}, 8.167 \mu \mathrm{g} / \mathrm{ml}, 12.509 \mu \mathrm{g} / \mathrm{ml}$, $2.085 \mu \mathrm{g} / \mathrm{ml}$ and $9.099 \mu \mathrm{g} / \mathrm{ml}$, respectively. However, varying degree of lethality of Artemia salina was observed with exposure to different dose levels of the test samples ranging from $0-800 \mu \mathrm{g} / \mathrm{ml}$ and further investigation regarding the cytotoxic property of Cryptocoryne ciliata needs to be studied.

\section{CONCLUSION}

The antioxidant and cytotoxic activities of various fractions of Cryptocoryne ciliata plant, found in this study, may explain some of the traditional medicinal uses of this plant. These could be of particular interest in relation to find out its unexplored efficacy and can be a potential source of chemically interesting and biologically important drug candidates.

\section{ACKNOWLEDGEMENT}

The authors are thankful to the staff of Phytochemical Research Laboratory, Faculty of Pharmacy, University of Dhaka for their assistance, kind suggestions and providing necessary infrastructure and all facilities during the study.

\section{REFERENCES}

Baker J.T., Borris R.P., Carte B. et al. (1995) Natural product drug discovery and development: New perspective on international collaboration, J Nat Prod, 58: 1325-1357. [DOI] PMid:7494142

Brand-Williams, W., Cuvelier, M. and Berset, C. (1995). Use of a free radical method to evaluate antioxidant activity, Lebensmittel-Wissens-chaft-und-Technologie, 28: 25-30.

Choi, H.Y., Jhun, E.J., Lim, B.O., Chung, I.M., Kyung, S.H., Park, D.K. (2000). Application of flow injection-chemilumineacence to the study of radical scavenging activity in plants, Phytother Res., 14: 250-253. [DOI]

Desmarchelier C., Repetto, M., Coussio, J., Liesuy, S. and Ciccia, G. (1997). Antioxidant and prooxidant activities in aqueous extracts of Argentine plants. Int J Pharmacog; 35: 116-120. [DOI]

Farombi E.O. (2003). African indigenous plants with chemotherapeutic potentials and biotechnological approach to the production of bioactive prophylactic agents. African J Biotech 2: 662-671.

Halliwell B., Gutteridge J.M.C.. (1989). Free radicals in biology and medicine. 2nd ed. Oxford: Clarendon Press.

McLaughlin J.L., Anderson J.E., Rogers, Lingling L (1998). Drug Info Journal; 32: 513-524. [DOI]

McLaughlin, J.L., Chang, C.J., Smith, D.L. (1991). Bench-top bioassays for the discovery of bioactive natural products: an update. In: Rhaman, A. U. (Ed.), Studies in Natural Products Chemistry. Elsevier, Pp: 383-409.

McLauglin, J.L., Chang, C.J., Smith, D.L. (1993). Simple bench-top bioassays (brine shrimp and potato discs) for the discovery of plant antitumour compounds. In: Human Medicinal Agents from Plants. Kinghorn, A.D. and Balandrin, M.F. (Eds.), ACS Symposium 534, American Chemical Society, Washington, DC, Pp: 112-137.

Meyer, B.N., Ferringni, N.R., Puam, J.E., Lacobsen, L.B., Nichols, D.E., McLaughlin, J.L. (1982). Brine shrimp: a convenient general bioassay for active constituents; Planta Medica, 45: 3132. [DOI]

Persoone, G. (1980). Proceeding of the International Symposium on Brine shrimp, Artemia salina, Vol. 1-3, Universa Press, Witteren, Belgium.

Stuffness M., Douros J. (1982). Current status of the NCI plant and animal product program, J Nat Prod, 45: 1-14. [DOI] 